\title{
Intrathecal Autologous Bone Marrow Derived MSC Therapy in Cerebral Palsy: Safety and Short Term Efficacy
}

\author{
Hala Gabr ${ }^{1,}$, , Wael Abou El-Kheir ${ }^{2}$, Osama Ghannam ${ }^{3}$, Mohamed Esewy El-Fiki ${ }^{4}$, Yehia Salah ${ }^{5}$ \\ ${ }^{1}$ Hematology, Faculty of Medicine, Cairo University, Cairo, Egypt \\ ${ }^{2}$ Immunology, Military Medical Academy, Cairo, Egypt \\ ${ }^{3}$ Neurosurgery, Faculty of Medicine, Azhar university, Cairo, Egypt \\ ${ }^{4}$ Neurosurgery, Faculty of Medicine, Alexandria University, Cairo, Egypt \\ ${ }^{5}$ Anaesthesia, Military Medial Academy, Cairo, Egypt
}

Email address:

halagabr@yahoo.com (H. Gabr), halagabr@kasralainy.edu.eg (H. Gabr)

\section{To cite this article:}

Hala Gabr, Wael Abou El-Kheir, Osama Ghannam, Mohamed Esewy El-Fiki, Yehia Salah. Intrathecal Autologous Bone Marrow Derived MSC Therapy in Cerebral Palsy: Safety and Short Term Efficacy. American Journal of Bioscience and Bioengineering. Special Issue: Stem Cells for Neuro-regeneration: Where Do We Stand. Vol. 3, No. 4-1, 2015, pp. 24-29. doi: 10.11648/j.bio.s.2015030401.14

\begin{abstract}
Objectives: Cerebral palsy (CP) is a disorder caused by injury or abnormal development of the brain at or immediately after birth. Current management of CP may improve the symptoms, such as muscle tone and gait, but is not directed to the original damage. Cellular therapy is evolving as a regenerative tool in many diseases with neural damage. Mesenchymal stem cells (MSCs) have been proven to transdifferentiate into neural lineage and improve neurodegeneration in animal models and in few clinical trials. This study was designed to evaluate the safety and efficacy of autologous MSC therapy in cases of CP. Subjects and Methods: this study is a randomized controlled trial enrolling 100 CP patients aged 1-7 years. Patients were assigned into two groups: Study group (44 patients after drop out cases) and control group (50 patients). All patients were subjected to history taking and clinical assessment. The study groups underwent bone marrow aspiration and MSC separation. MSCs were injected intrathecally. Follow-up was done using Child Health Questionnaire, Gross Motor Function classification System and Pediatric evaluation of disability inventory. Results: Overall assessment revealed improvement in motor, cognitive, or social parameters in 8 patients (18.18\%). Study group showed improvement in Child Health Questionnaire, Gross Motor Function Classification, but not Pediatric Evaluation of Disablity Inventory. No correlation was found between improvement and age or gender. Complications observed were transient related to injection, no neurological or radiological complications were observed. Conclusions: Autologous MSC injection in CP patients showed short-term safety, with variable efficacy in improving motor and cognitive defects.
\end{abstract}

Keywords: Cerebral Palsy, Cellular Therapy, Mesenchymal Stem Cells, Neuroregeneration

\section{Introduction}

Cerebral palsy (CP) is defined as a group of permanent non-progressive disorders of the development of movement and posture, causing activity limitation, that are attributed to non-progressive disturbance that occurred in the developing fetal or infant brain" (1).

$\mathrm{CP}$ is diagnosed clinically presenting as a number of neurological signs including spasticity, motor deficit, lack of coordination and impaired voluntary movement with nonselective command (2). Dystonic and mixed forms of cerebral palsy with damage of the extrapyramidal tract have also been described (3). The pathogenesis of cerebral palsy is still unclear; genetic and racial factors (4), birth weight (5), hypoxia, infections as well as prenatal factors may be involved (6). The annual incidence of cerebral palsy is around 2/1000 live births (7), a prevalence greatly exceeding that of spinal cord injury (8).

Currently, the therapeutic options for CP are limited. Medical intervention is restricted to anti-epileptic drugs in conjunction with symptomatic interventions such as new feeding techniques, orthopedic surgery and physiotherapy (7), intramuscular botulinum injections (8), selective dorsal rhizotomy (9), intrathecal baclofen (10) and targeted training (11).

As an acquired neurological deficit, the recent revolution in neuroregeneration applies to $\mathrm{CP}$. The old concept that 
neuroregeneration does not occur in the central nervous system has been challenged by many workers both in animal and human experiments(12).

Zhang et al demonstated the neuroprotective and neuroregenerative effect of cord blood derived stem cells injected in a rat model of stroke (13). Aly et al (2011) demonstrated the transdifferentiation ability of cord bloodderived mesenchymal stem cells towards all three neurological cell types (14). These two findings pave the way for neuro-regenerative therapeutic intervention for management of cerebral palsy. The finding of Aly et al (2011) introduce autologous stem cells as a convenient therapeutic option.

The aim of the present study was to evaluate the safety and short term clinical efficacy of cellular therapy in CP patients.

\section{Subjects \& Methods}

\subsection{Subjects}

This randomized controlled trial was conducted on 100 Egyptian patients with cerebral palsy from Rehabilitation and Physical Medicine Military Center, from June 2008 till June 2009. Study included 60 male and 40 female patients, ages ranging from 1 to 7 years. Institutional ethical committee approval and informed written consent were taken from one of the parents of the child.

Randomization was done using the envelope method: envelops were prepared with "case" and "control" written inside them. After drop out cases were cancelled, the treated cases were 44 and the control were 50 .

Patient Selection:

Inclusion Criteria:

1. Patients with cerebral palsy (all clinical types).

2. Age between 1-7 years.

Exclusion Criteria:

1. Patients with chromosomal abnormalities

2. Patients with history of seizures.

3. Patients with severe fixed deformities.

The patients were divided into 2 groups:

Group I (Study Group):

Included 50 patients

Group II (Control Group):

Included 50 patients with cerebral palsy

Both groups were allowed to continue their usual medical treatment (neurotropic drugs) and physiotherapy.

\subsection{Methods}

1. A written informed consent, from the parent(s) before enrollment of their child into the study.

2. Clinical evaluation : including

- Full history taking with special emphasis on prenatal, natal, postnatal, developmental history.

- Full neurological examination, CT brain and transcranial Doppler.

- Clinical measures of disability, including : a) Child Health Questionnaire (15).

b) Gross Motor function classification system for cerebral palsy patients (16).

c) Pediatric evaluation of disability Inventory(PEDI) (17) evaluating self care, mobility and social function.

3. Stem cell transplantation(STC) (in group I only ) :

- Bone marrow aspiration from the posterior iliac crest. 30-35 ml of bone marrow was aspirated on preservative-free heparin.

- Isolation and cultures of mesenchymal stem cell (MSCs):

a). Separation of mononuclear cells (MNC): Mononuclear cells layer was separated under aseptic conditions by density gradient centrifugation using Ficol-Hypaque at 1800 rpm for 20 minutes.

b). Cell culture:

a. Cells were cultured in a density of $1 \times 10^{6}$ in T25 tissue culture flasks in complete medium composed of low glucose DMEM, 20\% patient's autologous serum, $10 \% \quad$ L-glutamine and penicillin/streptomycin.

b. The tissue culture flasks were incubated in the humidified $\mathrm{CO} 2$ incubator at $37^{\circ} \mathrm{C}$ for 3 days without further handling.

c. After 3 days, non-adherent cells were discarded and the medium was refreshed. Medium was changed every 3 days until cells reached $80-90 \%$ confluence as examined using inverted microscope.

d. Cell harvest was done by trypsinization using $2.5 \%$ Trypsin-EDTA for 3-5 minutes at $37^{\circ} \mathrm{C}$. The action of trypsin was stopped by the addition of $1 \mathrm{ml}$ complete medium.

e. The collected cells were washed 3 times with PBS then evaluated for:

- Cell count using the hemocytometer.

- Viability testing using trypan blue dye exclusion test.

- Immunophenotyping using flowcytometry: Enumeration of the percentage of CD $45+\mathrm{ve}$ and mesenchymal stem cells markers:CD 44, CD 90, CD 105, CD 271 by flow cytometric analysis. All samples were analyzed on a Coulter Epics Elite flowcytometer. Sample processing was done immediately.

Reading and interpretation of results: Results were expressed as a percentage of cells expressing positive CD clusters within the gated population.

- Trilineage differentiation potential using mesenchymal stem cell identification kit (Stem Cells) which was done for some samples.

c). Cells were resuspended in sterile saline for injection in the patients. Cells were injected intrathecally under short-acting anaesthesia. 
The target dose of mesenchymal stem cells was $2 \times 10^{6}$ MSC / kg BW. The procedure was repeated 2-6 times until the target cell dose was reached.

4. Follow up of patients after one year by clinical, radiological and electrophysiological testing..

\subsection{Statistical Analysis}

The data were coded and entered using the statistical package social science (SPSS) version 12. Descriptive analyses were conducted using mean and standard deviation for quantitative variables. To test the significance of difference between quantitative variable of the same group (pre and post SCT) wilcoxon sign rank test was used, while Mann Whitney test was used in comparison of quantitative variables between cases and controls. When $\mathrm{P}$ was $<0.05$ this was statistically significant, when $\mathrm{P}$ was $<0.01$ this was statistically highly significant.

\section{Results}

\subsection{Isolation and Characterization of MSCs}

MSCs were identified by their spindle shape. Immunophenotyping revealed negative CD45 and variably positive for CD44, CD90, CD105 and CD271. Trilineage differentiation showed positive osteogenic, adipogenic and chondrogenic differentiation.

\subsection{Descriptive Data}

Distribution of age, gender, clinical presentation, and initial evaluation scales of patients in both groups is summarized in table 1. Mean age of the whole group was 4.8 \pm 2.4 years.

Table (1). Distribution of age, gender, clinical presentation and initial evaluation of scales in both groups.

\begin{tabular}{lll}
\hline Item & Group I & Group II \\
\hline Gender & & \\
Male & 24 & 26 \\
Female & 20 & 24 \\
Age: & & \\
Mean & 4.9 & 4.6 \\
S.D. & 1.1 & 1.4 \\
Type: & & \\
Spastic & 11 & 14 \\
Atonic & 32 & 34 \\
Athetotic & 1 & 2 \\
GMFCS: & & \\
Level II & 5 & 6 \\
Level III & 7 & 8 \\
Level IV & 12 & 14 \\
Level V & 20 & 22 \\
PEDI: & & \\
FS-sc & $29.72 \pm 9.12$ & $27.90 \pm 8.1$ \\
FS-mo & $17.39 \pm 5.9$ & $18.53 \pm 5.2$ \\
FS-sf & $31.25 \pm 9.7$ & $30.01 \pm 8.8$ \\
CA-sc & $14.89 \pm 5.2$ & $16.24 \pm 5.9$ \\
CA-mo & $9.68 \pm 4.5$ & $8.25 \pm 3.3$ \\
CA-sf & $10.68 \pm 4.1$ & $11.98 \pm 4.9$ \\
\hline
\end{tabular}

\subsection{Comparative Data}

Out of the 44 patients enrolled in the SCT group, 24 were males and 20 females. With mean age 4.9 years. The control group was 26 males and 24 females with mean age 4.6 years.

Overall assessment revealed improvement in motor, cognitive, or social parameters in 8 patients $(18.18 \%)$. One patient showed only motor improvement, one showed only cognitive improvement while the remaining 6 showed motor, cognitive and social improvement. Out of the improved cases, 5 were males and 3 were females. Mean age of the improved patients was 5.9 years while mean age of the nonimproved patients was 4.7 years.

\subsubsection{Child Health Questionnaire}

Follow up of the stem cell transplantation group showed significant improvement between pre- and post transplantation values. However, statistical analysis showed no significant difference between both groups, as regards physical, emotional and social well-being $(\mathrm{P}>0.05)$. (Table 2 , Figure (1))

Table (2). Mean Child Health questionnaire Scores in both groups before and after SC Therapy

\begin{tabular}{lllll}
\hline Scale & Group I & \multicolumn{3}{l}{ Group II } \\
\hline & Before & After & Before & After \\
\hline $\begin{array}{l}\text { Physical } \\
\begin{array}{l}\text { summary } \\
\text { Psychosocial } \\
\text { summary }\end{array}\end{array}$ & $37.3 \pm 14.2$ & $44.5 \pm 18.5$ & $31.8 \pm 15.5$ & $34.5 \pm 12.6$ \\
\hline
\end{tabular}

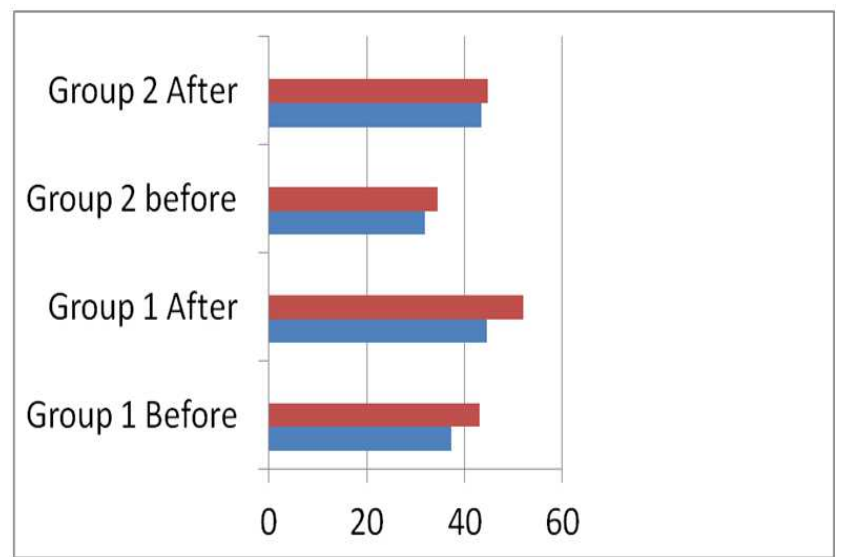

Figure (1). Mean Child Health questionnaire Scores in both groups before and after SC Therapy.

\subsubsection{Gross Motor Function Classification System for Cerebral Palsy}

A. Results of initial assessment of both groups:

No significant difference was observed between both groups on initial and follow-up assessment $(\mathrm{P}>0.05)$. However, a statistically highly significant improvement was observed after STC as compared to pre STC scores in group I $(\mathrm{P}<0.01)$; while no improvement was observed in the control group (Table 3 ). 
Table (3). Change in GMFCS in both groups at follow-up.

\begin{tabular}{lll}
\hline Parameter & Group I $(\mathbf{n}=\mathbf{4 4})$ & Group II $(\mathbf{n}=\mathbf{5 0})$ \\
\hline Unchanged: & & \\
-Number & 36 & 48 \\
-Percent & $81.81 \%$ & $96 \%$ \\
From V to IV: & & \\
-Number & 1 & 1 \\
-Percent & & \\
From V to III & 2 & 0 \\
From V to II & 1 & 0 \\
From IV to III & 2 & 0 \\
From IV to II & 1 & 0 \\
From III to II & 1 & \\
\hline
\end{tabular}

\subsubsection{Pediatric Evaluation of Disability Inventory}

No significant difference was observed between both groups on initial or follow-up assessment $(\mathrm{P}>0.05)$ (Table 4).

Table (4). PEDI scores.

\begin{tabular}{lllll}
\hline Parameter & Group I & \multicolumn{3}{l}{ Group II } \\
\hline & Before & After & Before & After \\
\hline FS-sc & $29.72 \pm 9.12$ & $32.90 \pm 8.00$ & $27.90 \pm 8.1$ & $28.90 \pm 7.56$ \\
FS-mo & $17.39 \pm 5.9$ & $22.45 \pm 6.91$ & $18.53 \pm 5.2$ & $18.55 \pm 5.6$ \\
FS-sf & $31.25 \pm 9.7$ & $37.12 \pm 10.12$ & $30.01 \pm 8.8$ & $31.00 \pm 7.98$ \\
CA-sc & $14.89 \pm 5.2$ & $16.23 \pm 6.56$ & $16.24 \pm 5.9$ & $17.00 \pm 6.23$ \\
CA-mo & $9.68 \pm 4.5$ & $11.56 \pm 4.24$ & $8.25 \pm 3.3$ & $8.12 \pm 4.25$ \\
CA-sf & $10.68 \pm 4.1$ & $13.24 \pm 4.56$ & $11.98 \pm 4.9$ & $12.55 \pm 5.01$ \\
\hline
\end{tabular}

\subsection{Correlation Data}

1. Age: No significant correlation was found between age of patients, in both groups, and scores of any of the used severity scales.

2. Gender: No significant correlation was found between gender of the patient and scores of the evaluation scales.

3. Correlation between motor and functional parameters: One patient showed only motor improvement, one showed only cognitive improvement while the remaining 6 showed motor, cognitive and social improvement. There was significant positive correlation between the improvement in these three parameters.

\subsection{Complications}

Mild transient complications were observed in the first week after injection in the form of transient fever $(20 \%)$ and meningism (14\%). No neurological, radiological or electrophysiological complications were seen after one year follow-up in any of the patients.

\section{Discussion}

Cerebral palsy is a static neurological deficit that results from brain injury occurring before full neurological development which is complete at two years of age (18). The limited therapeutic options available for $\mathrm{CP}$ patients lead to the search for neuroregenerative options such as cellular therapy. The therapeutic benefit of cellular therapy may be due to neuroprotection, neurorestoration, or neuroregeneration (REF) or secretion of neurotrophic cytokines (19).
Cellular therapy options for CP may be allogenic or autologous; since the insult is postnatal and not genetically determined. The stem cell sources for neuroregeneration may be embryonic, fetal, cord blood derived, bone marrow derived or adipose derived stem cells (20). A number of clinical trials were performed exploring the effect of stem cell therapy in CP patients exploiting bone marrow mononuclear cells, bone marrow CD133+ve cells, bone marrow mesenchymal stem cells, umbilical cord mononuclear cells and embryonic stem cells.

This study was performed to evaluate the safety and shortterm efficacy of autologous mesenchymal stem cell therapy in cerebral palsy patients. Diagnosis was done through history of perinatal insult, clinical evaluation, in addition to the absence of chromosomal aberrations. This study used autologous bone marrow derived mesenchymal stem cells. Autologous stem cell therapy is the preferred option for CP patients, since the injury is postnatal, with no genetic abnormality necessitating the use of allogenic stem cells. Bone marrow derived MSCs have been proven to have neuroregenerative effect in many animal and clinical studies (21,22,23).

Mesenchymal stem cells have proven safety and effectiveness in neurorestorative therapy in a number of settings (24). Bone marrow is the best source of MSCs (25). Bone marrow derived MSCs were isolated using the plastic adherence property and characterized guided by the criteria of international society for cell therapy (26). MSCs were delivered intrathecally as an effective, minimally invasive route for cellular therapy of central nervous system disorders. Patients were followed-up for one year using motor and cognitive scales: Child Health Questionnaire, gross motor function classification and pediatric evaluation of disability inventory (PEDI).

Child health questionnaire was measured using CHQparent form 50 (CHO-PF50). It consists of 50 questions answered by the parents covering several domains scaled from 0 to 100 with higher scores denoting better health related quality of life (HRQL). Scores are compared with the average scores for this age in the population (27). Vitale et al (2005) stated that CHQ-PF50 could discriminate the CP population as a function of severity (28).

Results showed an improvement rate of $18.18 \%$ ( 8 cases) in the form of motor, cognitive improvement or both. Motor improvement, as evidenced by GMFC score was evident in 6 cases (75\%) of improved cases: 2 cases showed an improvement of 2 levels, while 4 showed an improvement of 1 level. Cognitive improvement in the form of improved speech, improvement in social reactivity and alertness was demonstrated in 8 cases $(100 \%) 6$ of which were accompanied by motor improvement (75\%); while two cases (25\%) showed cognitive improvement only.

This is in accordance with the work of Romanov et al (2015) (29), Sharma et al (2015) (30), Zali et al (2015) (31), Wang et al (2015) (32), Shroff et al (2014) (33), and Mancias-Guerra et al (2014) (34). All these studies reported the safety of intrathecal injection of stem cells in CP patients. 
The previous studies vary, however, in the type of cell used. Romanov and coworkers used allogenic umbilical cord blood mononuclear cells. This is a heterogenous population that contains a small percentage of hemopoeitic stem cells and minimal numbers of mesenchymal stem cells. Wang et al used the mesenchymal cell fraction of the umbilical cord blood. Mesenchymal stem cells have documented neuroregenerative and neuroprotective effects (24). However, the use of purification for MSCs allows augmentation of their number. The use of allogenic cells necessitates HLAtyping. Bone marrow mononuclear cells were used by Sharma et al and Mancias-Guerra et al. Bone marrow mononuclear cells may be enriched for hemopoeitic, endothelial and mesenchymal stem cells than umbilical cord blood. Zali et al used bone marrow derived CD133 positive cells, which correspond to an early progenitor higher in hierarchy than hemopoeitic stem cells (31). CD133 positive cells have marked angiogenic properties, thus forming a favorable microenvironment for regeneration. On the other hand, Schroff et al (33)used embryonic stem cells for therapy. However, there are many ethical concerns regarding this methodology. The use of unfractionated mononuclear cells necessitates a high cell dose in order to provide the target stem cell dose; a procedure that may cause complications due to increased intracranial tension or due the immunological problems of injection of immunocompetent cells.

This study confirms the safety of intrathecal injection of autologous bone marrow derived MSCs in CP pediatric patients. Challenges exist, however, before the implementation of cellular therapy for CP. These challenges are both practical and theoretical. Practical challenges are optimization of cell dose, proper patient selection, and timing of interference. Theoretical challenges are determination of the mode of action of the injected cells in a trial both to augment the therapeutic efficiency and to ensure safety.

Limitations of the study are the lack of radiographic evidence of regeneration, which will be done in future studies.

\section{References}

[1] Rosenbaum P, Paneth N, Leviton A, Goldstein M, Bax M, Damiano D, Dan B and Jacobsson B (2007): A report: the definition and classification of cerebral palsy April 2006. Dev Med Child Neurol Suppl;109:8-14.

[2] Koman LA, Smith BP, Shilt JS.(2004): Cerebral palsy. Lancet;363:1619-31.

[3] Achache V, Roche N, Lamy J-C, Boakye M, Lackmy A, Gastal A, Quentin V and Katz R.(2010): Transmission within several spinal pathways in adults with cerebal palsy. Brain 133(5):1470-1483.

[4] Wu Y, Xing G, Fuentes-Afflick E, Danielson B, Smith L, and Gilbert W. (2011): Racial, Ethnic and Socioeconomic disparities in the prevalence of cerebral palsy. Pediatrics, 127:e674-e681.
[5] Moreno-De-Luca A, Ledbetter DH, Martin CL. (2012) : Genetic insights into the causes and classification of the cerebral palsies. Lancet Neurol 11(3):283-92.10.1016/S14744422(11)70287-3.

[6] Hermansen MC, Hermansen MG(2006): Perinatal Infections and Cerebral Palsy. Clin Perinatol 33:315-333.

[7] Oskouni M, Coutinho F, Dykeman J, Jette N, Pringshein T. (2013): An update on the prevalence of cerebral palsy: a systematic review and meta-analysis. Dev Med Child Neurol. 55(6):509-19.

[8] Basu AP and Clowry G (2015): Improving Outcomes in Cerebral palsy with early intervention: New translational approaches. Front Neurol 6:24.

[9] Corry IS, Cosgrove AP, Duffy CM, Taylor TC, Graham HK (1999): Botulinum toxin A in hamstring spasticity. Gait Posture 10;206-210.

[10] Vaughan CL, Subramanian N, Busse ME (1998): Selective dorsal rhizotomy as a treatment option for children with spastic cerebral palsy. Gait Posture 8:43-59.

[11] Albright AL (1996): Intrathecal baclofen in cerebral palsy movement disorders. J Child Neurol 11:S29-S35.

[12] Drobyshevsky A, Cotten CM, Shi Z, Luo K, Jiang R,Derrick M, Tracy ET, Gentry T, Goldberg RN, Kurtzberg J, Tan S (2015): Human Umbilical Cord Blood Cells Ameliorate Motor Deficits in Rabbits in a Cerebral Palsy Model. Dev Neurosci

[13] Zhang L, Li Y,Zhang C, Chopp M, Gosiewska A, Hong K (2011): Delayed administration of human umbilical tissuederived cells improved neurological functional recovery in a rodent model of focal ischemia. Stroke 42:1437-1444.

[14] Aly H, Mohsen I, Badrawi N, Gabr H, Aly Z, Akmal D (2011): Viability an neural differentiation of mesenchymal stem cells derived from the umbilical cord in perinatal hypoxia. J Perinatol 1-6.

[15] Landgraf JM, Abetz L, Ware JE (1996): Child health questionnaire (CHQ): a user's manual. Boston: The Health Institute. New England Medical Centre.

[16] Palisano BR Rosenbaum BP, Walter BS, Russel, D, Wood E, Galuppi B(1997): Development and reliability of a system to classify gross motor function in children with cerebral palsy. Dev Med Child Neurol 39:2214-223.

[17] Haley SM: Pediatric evaluation of disability inventory (PEDI) (1992): development, standardization, and administration manual. Boston: New England Medical Center Hospital, PEDI Research Group.

[18] Wu YW, Xing G, Fuentes-Afflick E, Danielson B, Smith LH, Gilbert WM (2011): Racial, Ethnic, and socioeconomic disparities in the prevalence of cerebral palsy. Pediatrics 127(3):e674-681.

[19] Kassis I, Grigoriadis N, Gowda-Kurkalli B, Mizrachi-Kol R, Ben-Hur T, Slavin S, Abramsky O, Darussis D(2008).: Neuroprotection and Immunomodulation with mesenchymal stem cells in chronic experimental autoimmune encephalomyelitis. Arch Neurol. 65(6):753-761.

[20] Ilic D and Polak JM.(2011): Stem cells in regenerative medicine: introduction. Br Med Bull 98 (1): 117-126. 
[21] Banerjee S, Williamson D, Habib N, Gordon M, Chataway J (2011): Human stem cell therapy in ischaemic stroke: a review. Age Ageing 40 (1): 7-13.

[22] Hyun JK, and Kim HW (2010): Clinical and Experimental Advances in Regeneration of Spinal Cord Injury. J Tissue Eng Jan-Dec.

[23] Vale S (2008): Current management of the cognitive dysfunction in Parkinson's Disease: How far have we come? Exp Biol Med 233 (8): 941-951.

[24] Cameron SH, Alwakeel AJ, Goddard L, Hobbs CE, Gowing EK, Barnett ER, Kohe, SE, Sizemore RJ, Oorscho DE (2015): Delayed post-treatment with bone marrow-derived mesenchymal stem cells is neurorestorative of striatal medium-spiny projection neurons and improves motor function after neonatal rat hypoxia-ischemia. Mol Cel Neurose doi:10.1016/j.men.2015.03.019.

[25] Hass R, Kasper C, Bohm S and Jacobs R (2011): Different populations and sources of human mesenchymal stem cells (MSC): A comparison of adult and neonatal tissue-derived MSC. Cell Commun Sig 9:12.

[26] Dominici, M., K. Le Blanc, I. Mueller, I. Slaper-Cortenbach, F. Marini, D. Krause, R. Deans, A. Keating, D. Prockop, E. Horwitz: Minimal criteria for defining multipotent mesenchymal stromal cells: The International Society for Cellular Therapy position statement. Cytotherapy 8: 315-317 (2006).

[27] McCullough N and Parkes J: Use of the Child Health Questionnaire in Children with Cerebral palsy: a Systematic Review and Evaluation of the Psychometric Properties. J Pediatr. Psychol. 33:80-90 (2008).

[28] Vitale MG, Roye AE, Choe JC, Heymann JE, Ley FY, Roye DP: Assessment of health status in children with cerebral palsy: What is the role of quality of life measures. Journal of Pediatric Orthopedics 25(6): 792-797.
[29] Romanov YA, Tarakanov OP, Radaev SM, Dugina TN, Ryaskina SS, Darevskya AN, Morozova YV, Khachatryan WA, Lebedev KE, Zotova NS, Burkova AS, Sukhikh GT, Smirnov VN (2015): Huan allogeneic ABO/Rh-identical umbilical cord blood cells in the treatment of juvenile patients with cerebral palsy. Cytotherapy S14653249(15)00074-2. doi:

[30] Sharma A, Sane H, Gokulchandran N, Kulkarni P, Gandhi S, Sundaram J, Paranjape A, Shetty A, Bhagwanani K, biju H, Badhe P (2015): A clinical study of autologous bone marrow mononuclear cells for cerebral palsy patients: a new frontier. Stem Cells Int 2015:905874.

[31] Zali A, Arab L, Ashrafi F, Mardpour s,Niknejhadi M, Hedayati-Asl AA, Halimi-Asl A, Ommi D, Hosseini SE, Baharvand H,Aghdami N (2015): Intrathecal injection of CD133-positive enriched bone marrow progenitor cells in children with cerebral palsy: feasibility and safety. Cytotherapy 17(2):232- 41.

[32] Wang $\mathrm{X}, \mathrm{Hu} \mathrm{H}$, Hua R, Yang J, Zheng P, Niu X, Cheng H, Dai G, Liu X, Zhang Z, An Y (2015): Effect of umbilical cord mesenchymal stromal cells on motor functions of identical twins with cerebral palsy: pilot study on the correlation of efficacy and hereditary factors. Cytotherapy 17(2):224-31.

[33] Shroff G, Gupta A, Barthakur J (2014): Therapeutic potential of human embryonic stem cell transplantation in patients with cerebral palsy. J Transl Med 12(1):318.

[34] Mancieas-Gurerra C, Marroquin-Escamilla AR, GonzalezLlano O, Villarreal-Martinez L, Jaime-Perez JC, GarcaRodriguez F, Valdes-Burnes SL, Rodriguiez-Romo IN, Barrera-Morales DC, Sanchez-Hernandez JJ, CantuRodriguez OG, Gutierrez-Aguirre CH, Gomez-De Leon A, Elizondo-Riojas G, Salazar-Riojas R, Gomez-Almaguer D (2014): Safety and tolerability of intrathecal delivery of autologous bone marrow nucleated cells in children with cerebral palsy: an open-label phase I trial. Cytotherapy 16(6):810-20. 